\title{
Rosemary Oil
}

National Cancer Institute

\section{Source}

National Cancer Institute. Rosemary Oil. NCI Thesaurus. Code C107360.

The essential oil of Rosmarinus officinalis. Rosemary oil is used primarily for its aromatic properties. 